\title{
CHALLENGES IN EDUCATING MUSEUM PROFESSIONALS FOR THE 21ST CENTURY. THE MU.SA - MUSEUM SECTOR ALLIANCE PROJECT
}

\author{
P. Homem, M. Pinto \\ Faculty of Arts and Humanities of University of Porto (PORTUGAL)
}

\begin{abstract}
This paper aims to present the Mu.SA - Museum Sector Alliance project, funded by the European Commission, more specifically by the Erasmus+ Program and the Key Action 2 (Cooperation for Innovation and Good Practice Exchange), which supports the Sector Competences Alliances (575907EPP-1-2016- 1-EL-EPPKA2-SSA).

Building on the results of a previous project (eCult Skills_2013-15), funded by the Lifelong Learning Program, weaknesses in the museum sector were identified at the level of digital and transversal competences. The Mu.SA project intended to contribute to the mitigation of these fragilities, in order to empower museum professionals, as well as those who aspire to be, to better face the challenges of Information and Communication Technologies and to enhance their museums and Society by promoting their development and sustainability, building on larger and stronger synergies between different sectors of education, training and youth, for the better articulated interaction between research, policies and practices and for the best use of references for recognition and validation of competences and qualifications.

Thus, based on the identification and characterization of a set of emerging professional profiles and respective competences, the Mu.SA - Museum Sector Alliance aimed at, and has been, developing an Open Educational Resources repository to support individual equipping in more than forty digital and transversal competences. These duly structured resources are offered in different formats of education and training courses: a Massive Open Online Course (MOOC), certified and of a generic and introductory nature; and a Specialization Course, credited and structured considering e-learning, face-to-face and work-based learning contexts.

The legitimate and reasoned expectation of building communities of practice will also contribute to ensuring the sustainability of the results, beyond the duration of the project. Among the other positive expected results, at the level of those more or less directly involved in its activities, there may be an increase in the spirit of initiative and entrepreneurship, a more active participation in Society, a greater capacity for understanding, respect and response.
\end{abstract}

Keywords: Museum professionals, digital \& transversal competences, education needs, Mu.SA Museum Sector Alliance project.

\section{INTRODUCTION}

A new age of digital is here: that of Digital Transformation! Like all sectors of Society, museums are not immune to it and struggle for their adaptation, fearing that, if they do not, they will not be able to fulfil their mission and will not survive with quality or even not survive at all. They know that more than just adopting technology, it will be important to adopt a digital culture and, through technology, enhance human capital, promoting experiences, engaging and building up loyal audiences, and (inter)actively involving them in their dynamics. In this upgrading effort, at service of Society, museums have paved the way for new fields of work and employment.

Museum professionals are well aware of the potential and challenges that such a transformation entails. Their academic background is usually superior and even specialized through postgraduate education that considers the important traditional functions of a museum: collecting, conserving, researching, exhibiting and educating [1]. They know museums have to take care of their collections as well as to ensure to be and to keep on being valuable and relevant to future generations, which is to create a sustainable future, and are aware of the importance of aligning digital strategies to the wider institution [2]. Nevertheless, and in line with the European Commission's diagnosis [3], they 
suffer from a professional Information and Communications Technology (ICT) skills shortage and a digital literacy deficit.

The upgrading of museum professionals' competences through continuous education courses is recognized by themselves as important for the development of museums, defended and demanded by their worldwide professional organization, the International Council of Museums (ICOM), specifically by its International Committee for the Training of Personnel (ICTOP) [4], and it's a guideline that supports the principles of their Code of Ethics for desirable professional practice [5].

In order for professional practice to be desirable, the new reality and emergence of new job roles require the updating of museum professionals not only in the area of ICT but also in transversal competences. We assume the CEDEFOP's definition of: competence, as the "ability to use knowledge, skills and personal, social and/or methodological abilities, in work or study situations and in professional and personal development" [6]; digital competence, as the "ability to use information and communication technology (ICT)" [6]; and transversal competence as those "which have been learned in one context or to master a special situation/problem and can be transferred to another context" [7].

However, dedicated continuing education courses are non-existent or residual. So, the quickening pace of the adoption of ICT in the museum sector reveals a disconnection between the needs of the work context and the formal education and training context. It was this, increasing, disconnection that the Mu.SA - Museum Sector Alliance project [8] aimed to address. Selectively and more specifically, the Mu.SA project focussed on: i) the identification of European profiles of emerging job roles in museums that could serve as a common reference at European level, and respective competences; ii) the planning and design of a modular VET curriculum that dynamically combines training modules for digital and transversal competences, as contribution to a European standard for learning outcomes, considering a Massive Open Online Course (MOOC) for acquiring the basic competences and promoting the establishment of European communities of practice, and a European specialization course that can be adapted to national needs and combines phases of e-learning, face to face training and work-based learning.

The consortium, coordinated by the Hellenic Open University ( $\mathrm{HOU})$, gathered 11 partners from 4 European Countries, specifically Belgium, Greece, Italy and Portugal, allying different sectors:

- European Sectorial Umbrella: Culture Action Europe (CAE, Belgium);

- Museum sectorial organizations: the Greek and Portuguese ICOM Commissions (ICOM Greece and ICOM Portugal); the Foundation for Italian Qualities (Symbola, Italy); the Institute for the Cultural and Natural Artistic Heritage of the Emilia Romagna Region (IBACN, Italy); Melting Pro Learning (MeP, Italy) and Mapa das Ideias (Mapa, Portugal), two small/medium size enterprises;

- Vocational Education and Training (VET) providers: Anonymous Educational Organization (AKMI, Greece); HOU (Greece); Link Campus University (LCU, Italy); and the University of Porto (U.PORTO, Portugal).

The Mu.SA project will be finished by the end of April 2020 and it has been funded by the European Commission, more specifically by the Erasmus+ Program and the Key Action 2 (Cooperation for Innovation and Good Practice Exchange), which supports the Sector Competences Alliances (575907EPP-1-2016- 1-EL-EPPKA2-SSA).

\section{METHODOLOGY}

The research related to the identification of European profiles of emerging job roles in museums capitalised the results of a previous project, eCult Skills (2013-15), funded by the Lifelong Learning Programme (LLP) of the European Commission, which focussed on the competences needed for professionals in the museum sector to become proficient in the use of digital technologies in the field of culture. The eCult Skills adopted the European Framework for e-Competence (e-CF) in the specific field of e-Culture. This is a framework for improving the mobility and transparency of ICT professionals across Europe developed by the working group of the European Standardization organization on ICT Competences, according to the European Qualification Framework (EQF). As result, the eCult Skills project outlined five emergent job role profiles [9]: i) Cultural ICT consultant; (ii) Cultural ICT Guide; iii) Digital Cultural Assets Manager; (iv) Interactive Cultural Experience Developer; and (v) Online Cultural Community Manager. 
The Mu.SA partners reviewed these results aiming at understanding whether the five role profiles identified were still relevant for the museum sector and at selecting the most important competences needed to be developed for museum professionals. Aiming also at encouraging greater job mobility for museum professionals, they used the same European Framework, e-CF, adopted a qualitative approach and assumed a common research methodology.

By means of interviews and a focus group in each country, the social partners representing the museum sectorial organizations carried out a mapping activity of museum professionals' needs, trying to identify those related to transversal and to digital/e-competences. Meanwhile, the VET providers carried out a mapping of training provisions for museum professionals, conducting desk research and an online survey, aiming at characterize the current situation concerning the global approach and the rate of diffusion of training programs offered (formal, informal and non-formal) related to the competences of interest [10].

The planning and design of the modular VET curriculum respected the EQF universe of concepts [11] and were grounded on data collected, assuming a methodology based on learning outcomes, policies and tools for assessment and validation of informal/non-formal learning. The methodology [12], adopting an outcome-based approach, assumed a learner-centred model and focussed on what the trainees would learn, master and be able to do, as they progressed through the educational and training programme.

Targeting high quality, in writing the learning outcomes, Benjamin Bloom's taxonomy was addressed, exclusively the Cognitive domain (knowledge-based) [13] and its six levels' revised structure, and specific techniques were assumed, according to convenience:

- The one introduced by Mager [14], known as $A B C D$, which includes four main elements: Audience (Who? Who are the learners?), Behavior (What? What is it expected them to be able to do?), Condition (How? Under what circumstances or context will the learning occur?), and Degree of Mastery (How much? How much will be accomplished, how well will the behavior need to be performed, and to what level? Is it wanted total mastery $(100 \%)$, is it wanted them to answer correctly $80 \%$ of the time, etc. A common, and totally non-scientific, setting is $80 \%$ of the time);

- The one developed by Anderson, et al [15], known as SMART, which stands for Specific, Measurable, Attainable (or Action-oriented), Relevant, and Time-Bound.

As instructional design methodology, the well-known ADDIE (Analysis, Design, Development, Implementation and Evaluation) model was assumed and templates of the basic elements were produced. The process provided a continuous assessment in every step, where the quality of the outcomes in each phase was ensured by three roles assumed by: the author, responsible for content design and development; the technical reviewer, who monitored the intermediate outcomes and made sure that they followed the instructions and filled in the templates in appropriate way; and the scientific reviewer, who validated the contents [12].

\section{RESULTS}

The data collected provided useful insights into which role profiles and related competences need to be developed for museum professionals. Nevertheless, although some general considerations may be applied to the museum sector in Europe, caution must be taken when attempting to generalize the results of the research as they relate to the specific context of the analysed countries (Greece, Italy and Portugal) and due to the change dynamic concerning technology and subsequent training needs.

\subsection{The identification of European profiles of emerging job roles in museums and transversal and digital competences of interest}

The five emergent job role profiles outlined by the eCult Skills project consortium were submitted to appreciation and active discussion within the context of 3 focus groups (one per country), involving 32 participants in total, and of 49 interviews, for mapping museum professionals' needs. The group of participants included: Professionals and external collaborators recognized as experts in the museum sector also from the fields of research, policy and ICT; Directors of big and small, urban and rural museums, as well as regional or national museum networks; and Professionals with other roles in the context of museums, such as communication strategists, exhibition management experts, and educational experts. 
The desk research for mapping museum training provisions analysed 130 formal and informal educational training programs in all three countries, focusing on their relationship with the ecompetences of the five role profiles defined within the eCult Skills project. The data that was gathered regarding formal education consisted of graduate and postgraduate programs (Master and PhD) provided by Higher Education Institutions, as presented on their websites. It was analysed on the basis of specific indicators such as: Information about the provider (name of university/department, course/module, description, type of training, methodology, subjects, target group, prerequisites, duration, assessment methods etc.); Identification of the specific e-competences of the five job role profiles that the programme/course/module provided.

Regarding non-formal and informal training programs, in the three countries involved there were no lists, either official or non-official, of the relevant education providers, nor was there a database that specifically considered the museum sector. Therefore, the research focussed on those training activities for the museum sector provided by known, recognised as relevant national associations.

The online survey collected 265 complete responses. The survey was open for 23 days. The short opening period, together with the lack of knowledge and public discussion related to the five role profiles under focus and respective e-competences, not recognized by professionals as having application in the national context, may justify the level of participation. However, in terms of impact, the number was much higher, recording 980 people opening the survey [10].

\subsubsection{The most important job role profiles in which museums should invest}

All data collected indicated the need for revision of the five emergent role profiles under research. The majority of all participants considered that the most important role profiles, in which museums should invest by up-skilling their professionals, were the following four, in brief and in order of priority [10]:

1 Digital Strategy Manager. Also known as Cultural ICT Consultant, Digital Cultural Manager, Cultural Digital Strategy Manager, Cultural ICT Ambassador, Digital cultural mediator, Cultural ICT Advisor, and Cultural ICT Specialist.

A strategic role profile for museums that aims to thrive in a digital environment, in line with the overall museum's strategy.

2 Digital Collections Curator. Also known as Digital Cultural Asset Manager, Digital Asset Manager, Born-Digital Material Curator, and Digital Curator.

This role profile is specialized in preserving and managing born-digital and digitalised materials. Develops online and offline exhibitions and content for other departments.

3 Digital Interactive Experience Developer. Also known as Interactive Experience Developer, Digital Interactive Experience Designer, and Exhibit Interactive Designer.

This role profile is specialized in designing, developing and implementing innovative and interactive experiences providing a meaningful experience for all types of visitors.

4 Online Community Manager. Also known as Online Cultural Community Manager, Online Community Developer, Online Community Specialist, Social Media Specialist, Digital Media Curator, Visual Media Curator, New Media Manager, Digital Communication Manager, and Social Media Manager.

This role profile aims to invest in developing and engaging diverse audiences online, and should be fully integrated into the institutional structure.

\subsubsection{Competences for the job role profiles}

The Mu.SA partners structured the identified four job role profiles according to the e-CF 3.0 recommendations, as it happened previously within the eCult Skills project, taking into account its divided structure into different dimensions: Dimension 1 (5 e-CF areas: A - Plan; B - Build; C - Run; D - Enable; E - Manage); Dimension 2 (40 e-Competences identified); Dimension 3 (e-Competence proficiency levels: e-1 to e-5, related to EQF levels 3 to 8 ); Dimension 4 (where samples of knowledge and skills reporting to e-Competences in dimension 2 are provided, just to add value and context and not to be exhaustive) [16].

These 40 e-competences are frequently required in the workplace today, establishing a shared terminology for competences and proficiency levels that can be understood all over Europe. That's the 
reason why this framework has been identified as the most effective for ensuring a higher degree of mobility and transparency for digital workers across Europe.

So, for each profile, transversal and e-competences have been listed by order of importance, ranked by the experts who have been consulted during the research activities, and the ones which are mandatory or optional for the role described according to levels Required or Desired: e-1 to e-5, related to EQF levels 3 to 8 .

According to the research outcomes there are, from the total set, some transversal and ecompetences that should be developed across all the four job role profiles and that should be considered essential as a starting point for professionals' up-skilling, as systematised in Table 1.

Table 1. The most important competences to develop across the 4 profiles [10].

\begin{tabular}{|c|c|c|c|}
\hline & $\begin{array}{l}\text { Transversal } \\
\text { competences }\end{array}$ & \multicolumn{2}{|c|}{$\begin{array}{l}\text { e-Competences identified from the } \\
\text { European e-Competence Framework } 3.0\end{array}$} \\
\hline Digital Strategy Manager & $\begin{array}{l}\text { Leadership and Change } \\
\text { Facilitator }\end{array}$ & $\begin{array}{l}\text { A.1. IS and Museum } \\
\text { Strategy Alignment }\end{array}$ & $\begin{array}{l}\text { A.3. Business Plan } \\
\text { Development }\end{array}$ \\
\hline Digital Collections Curator & Time Management & $\begin{array}{l}\text { A.4. Product/Service } \\
\text { Planning }\end{array}$ & $\begin{array}{l}\text { A.7. Technology Trend } \\
\text { Monitoring }\end{array}$ \\
\hline Digital Interactive Experience & Creative Thinking & A.9. Innovating & C.1. User Support \\
\hline Developer & Communication & $\begin{array}{l}\text { D.11. Needs } \\
\text { Identification }\end{array}$ & $\begin{array}{l}\text { E.1. Forecast } \\
\text { Development }\end{array}$ \\
\hline Online Community Manager & Team Working & $\begin{array}{l}\text { E.4. Relationship } \\
\text { Management }\end{array}$ & $\begin{array}{c}\text { E.6. ICT Quality } \\
\text { Management }\end{array}$ \\
\hline
\end{tabular}

Based on the data collected, the Mu.SA consortium assumed as important to also considered another European Framework, besides e-CF: the Digital Competence Framework for Citizens (DigComp), which was prepared by the Human Capital and Employment Unit (Joint Research Center) on behalf of the Directorate General for Employment, Social Affairs and Inclusion of the European Commission. The DigComp Framework has five dimensions: 1, Competence areas identified to be part of digital competence; 2 , Competence descriptors and titles that are pertinent to each area; 3 , Proficiency levels for each competence; 4, Knowledge, skills and attitudes applicable to each competence; and 5, Examples of use, on the applicability of the competence to different purposes. It describes 21 competences classified and organized into five competence areas: 1, information and data literacy; 2 , communication and collaboration; 3 , digital content creation; 4, safety; and 5, problem solving [17]. These competences are necessary to use digital technologies in a confident, critical, collaborative and creative way, in order to achieve goals related to work, employability, learning, leisure, inclusion and participation in Society.

For each role profile, a Description File has been created, considering: Title; Mission; Academic Qualification Sector (recommended); Level (according to EQF); Tasks/Key Responsibilities; Knowledge; e-competences (Proficiency Levels e-1 to e-5, Required and Desired, Very important and Important, Mandatory or Optional); Transversal competences (Very important and Important); Environment; Key Performance Indicators (KPI); and Relationships/Reporting line/Answerable to.

\subsection{The modular European VET curriculum}

Based on the previous research and results, the Mu.SA consortium developed a modular VET curriculum, with training modules supported by digital Open Education Resources (OER) that lead to the acquisition of a set of 64 competences, in total, considering e-CF, DigComp and Transversal $\left(21^{\text {st }}\right.$ Century) competences, as well as both the foreseen MOOC and the Specialization pilot courses. Its distribution is presented in Table 2. 
Table 2. Number and type of competences developed within the modular VET curriculum.

\begin{tabular}{c|c|c|c|c|c|c|c}
\hline \hline & \multicolumn{3}{|c|}{ MOOC } & \multicolumn{3}{c|}{ Specialization } & \\
\cline { 2 - 8 } & $\begin{array}{c}\text { Digital } \\
\text { (e-CF) }\end{array}$ & $\begin{array}{c}\text { Digital } \\
\text { (DigComp) }\end{array}$ & $\begin{array}{c}21^{\text {st }} \\
\text { (Trans.) }\end{array}$ & $\begin{array}{c}\text { Digital } \\
\text { (e-CF) }\end{array}$ & $\begin{array}{c}\text { Digital } \\
\text { (DigComp) }\end{array}$ & $\begin{array}{c}2^{\text {st }} \\
\text { (Trantury }\end{array}$ & Total \\
\hline Total & 8 & 9 & 5 & 21 & 6 & 15 & 64 \\
\hline \hline
\end{tabular}

\subsubsection{The MOOC}

A MOOC for acquiring the basic competences of the four job role profiles was made available to all museum/culture professionals in Europe and worldwide. The subject matter of the course attracted significant interest, given the high number of registrations: 5200. Registration data show the following geographical configuration: 35\% from Italy, 22\% from Greece, 11\% from Portugal, including 32\% from other countries.

During 8 weeks and for 80 hours of study (10 hours per week on average), all participants were delivered a total of 22 competences, according to Table 3.

Table 3. Competences of the Mu.SA MOOC.

\begin{tabular}{|c|c|c|c|}
\hline Week & Module & Competence & Type \\
\hline \multirow[t]{3}{*}{ W1 } & W1.1 & IS and business strategy alignment & e-CF \\
\hline & W1.2 & Browsing, searching and filtering data, information and digital content & DigComp \\
\hline & W1.3 & Managing data, information and digital content & DigComp \\
\hline \multirow[t]{3}{*}{ W2 } & W2.1 & Business Plan Development & e-CF \\
\hline & W2.2 & Evaluating data, information and digital content & DigComp \\
\hline & W2.3 & Identifying needs and technological responses & DigComp \\
\hline \multirow[t]{3}{*}{ W3 } & W3.1 & Technology trend monitoring & e-CF \\
\hline & W3.2 & Netiquette & DigComp \\
\hline & W3.3 & Leadership and change facilitator & $21^{\text {st }}$ Cent. \\
\hline \multirow[t]{3}{*}{ W4 } & W4.1 & Innovating & $\mathrm{e}-\mathrm{CF}$ \\
\hline & W4.2 & Innovating and creatively using technology & DigComp \\
\hline & W4.3 & Creative thinking skills & $21^{\text {st }}$ Cent. \\
\hline \multirow[t]{3}{*}{ W5 } & W5.1 & Needs identification & e-CF \\
\hline & W5.2 & Developing digital content & DigComp \\
\hline & W5.3 & Collaborating through digital technologies & DigComp \\
\hline \multirow[t]{2}{*}{ W6 } & W6.1 & Forecast development & e-CF \\
\hline & W6.2 & Team working & $21^{\text {st }}$ Cent \\
\hline \multirow[t]{2}{*}{ W7 } & W7.1 & Relationship management & $\mathrm{e}-\mathrm{CF}$ \\
\hline & W7.2 & Protecting personal data and privacy & DigComp \\
\hline \multirow[t]{3}{*}{ W8 } & W8.1 & ICT quality management & e-CF \\
\hline & W8.2 & Communication skills & $21^{\text {st }}$ Cent. \\
\hline & W8.3 & Time management & $21^{\text {st }}$ Cent \\
\hline
\end{tabular}

Each e-CF competence was taught in about 5 hours of study (for e-4 level equivalent to EQF 7, plus 2 hours for e-5 level equivalent to EQF 8). Each DigComp competence was taught in 1-2 hours of study, whereas each $21^{\text {st }}$ century (transversal) competence was taught in approximately 3 hours of study. Every module consisted of 2 to 5 units (learning activities). In each unit (learning activity) an educational strategy was applied in order to deliver any combination of core learning objects (video, presentation...), additional educational material (e-books, additional readings...), collaboration objects (forum...), and assessment objects (projects, self-evaluation exercises, quizzes...). 


\subsubsection{The Specialization}

The Specialization course, which considers the four job role profiles and gives sequence to the MOOC, started on September 16, 2019 and will finish on March 8, 2020.

The course combines a Blended Learning phase with a Work-Based Learning. The Blended Learning phase will last 24 weeks ( 6 months), with an effort of approximately 15 hours of study/week (totally 360 hours of study), including: Online and Self-study (288 hours); Face-to-face sessions (24 hours $=6$ x 4 hours) (once a month); and Assessment (48 hours). The Work-Based Learning will last 10 weeks or 205 hours in total, considering 200 hours of practical learning in a museum or cultural organization and 5 hours of assessment.

Those trainees from Greece, Italy and Portugal who successfully finished the MOOC were eligible for the Specialization. After a meticulous process, 120 candidates were selected by the Mu.SA Steering Committee Group, taking into account the applications and the accompanying documents submitted on time, as well as the guidelines and requirements of the engaged museums and cultural organizations that will host the Work-Based Learning.

The learner will be specialized in digital and transferable competences according to the role profile selected. In total, a set of 42 competences are being/will be provided for museum professionals, namely:

- 21 advanced digital competences from e-CF: Service Level Management, Product/Service Planning, Application Design, Sustainable Development, Application Development, Testing, Solution Deployment, Documentation Production, User Support, Change Support, Service Delivery, Problem Management, Information Security Strategy Development, ICT Quality Strategy Development, Education and Training Provision, Purchasing, Information and Knowledge Management, Digital Marketing, Risk Management, Process Improvement, and Business Change Management;

- 6 basic digital competences from DigComp: Copyright and Licenses, Programming, Solving Technical Problems, Protecting Personal Data and Privacy, Identifying Digital Competences Gaps and Managing Digital Identity;

- 15 transversal $\left(21^{\text {st }}\right.$ century) competences: Mentoring/Coaching, Analyse and Synthesize Information, Negotiation, Networking, Sense of Initiative and Entrepreneurship, Resilience, Decision Making, Management, Interpersonal, Mediation, Influence/Persuasion, Active Listening, Storytelling, Fact-driven, Integrity/Ethical.

ECVET will be awarded to each module.

\section{CONCLUSIONS}

Preparing museum professionals for all the added challenges that the $21^{\text {st }}$ century brought is not a simple process, especially when it's aimed to facilitate the recognition of learning and mobility.

Along with the research activities many other were organised in order to involve as many as possible in the discussion focussed on Mu.SA's thematic of concern. From those, are worth the highlight the three main conferences already held in Athens (Digital Challenges for Museum Experts, November 25, 2016), in Rome (Re-designing Museums. Digital Skills for Change and Innovation, July 13, 2017) and in Porto (+ Digital Future: Competences for the Cultural Sector, April 18, 2018) and the final one scheduled for Brussels, in April 1-3, 2020.

Although the hard work, it has been given good results, considering not only the interest, dedication devoted to learning from museum/culture professionals and their good performance, but also in terms of quality recognition:

In 2018, Mu.SA has been included in the DigComp User Guide as one of the 38 existing inspiring practices of DigComp implementations, and selected as one of the 9 best cases that use DigComp for employment. Also, the project has been proposed as Good Practice under the Initiative 8 - Heritagerelated skills - Component 3: Opportunities for cultural heritage professionals by European Commission;

In 2019, at the Awards Ceremony of the Portuguese Association of Museology (APOM 2019 Awards), the Mu.SA was prized with an Honourable Mention in the International Project category. 
By up-skilling and re-skilling of museum professionals, the Mu.SA project will enable museums to offer enhanced experiences, thus raising the quality of life of the general public. By collaborating with all stakeholders, it will deliver the right employability competences, thus increasing the efficiency and inclusiveness of VET institutions and the outreach and sustainability of museums.

\section{ACKNOWLEDGEMENTS}

The authors would like to express their acknowledgements to all colleagues of the Mu.SA - Museum Sector Alliance Project consortium, as well as to all who have been collaborating with it.

\section{REFERENCES}

[1] ICOM, Museum Definition, Accessed 2 September, 2019. Retrieved from https://icom.museum/en/activities/standards-guidelines/museum-definition/.

[2] AXIELL, Digital Transformation in the Museum Industry. Museums Report. Manchester: AXIELL Archives, Libraries, Museums, 2016.

[3] EU, A Digital Agenda for Europe. Brussels: European Commission, 2010.

[4] A. Ruge, "Introduction" in Museums Professions - A European Frame of Reference (A. Ruge, ed.), pp. 5 - 13, Paris: ICTOP-ICOM, 2008.

[5] ICOM, Code of Ethics for Museums. Paris: International Council of Museums, 2013.

[6] CEDEFOP, Terminology of European Education and Training Policy. A Selection of 130 Key Terms. 2 ed.. Luxembourg: Publications Office of the European Union, 2014.

[7] CEDEFOP, European Training Thesaurus. Luxembourg: Office for Official Publications of the European Communities, 2008

[8] Mu.SA - Museum Sector Alliance, Website, Home. Accessed 02 September, 2019. Retrieved from: http://www.project-musa.eu/.

[9] eCult Skills, Website, Project results. Accessed 02 September, 2019. Retrieved from: http://groupspaces.com/eCult/pages/project-results

[10] Silvaggi, A., ed. Museum Professionals in the Digital Era. Agents of Change and Innovation. Bologna: Centro Stampa Regione Emilia-Romagna, 2017.

[11] C.E. Union, "Council Recommendation, of 22 May 2017, on the European Qualifications Framework for Lifelong Learning and Repealing the Recommendation of the European Parliament and of the Council of 23 April 2008 on the Establishment of the European Qualifications Framework for Lifelong Learning", Official Journal of the European Union, C 189, 03, pp.15-28, 2017.

[12] Pierrakeas, C., et al., Design of Vet Curricula. Brussels: Mu.SA - Museum Sector Alliance, 2018.

[13] B.S. Bloom, ed. Taxonomy of educational goals: The classification of educational goals. Handbook I: Cognitive domain. New York: David McKay Company, 1956.

[14] R.F. Mager, Preparing Instructional Objectives: A Critical Tool in the Development of Effective Instruction. 3 ed.. Atlanta: Center for Effective Performance, 1997.

[15] L.W. Anderson, et al., eds. A Taxonomy for Learning, Teaching, and Assessing. The Revision of Bloom's Taxonomy of Educational Objectives. A Bridged Edition ed.. New York: Addison Wesley Longman, Inc., 2001.

[16] CEN. European e-Competence Framework 3.0. A common European Framework for ICT Professionals in all industry sectors. CWA 16234 Part 1. CEN-CENELEC, 2014.

[17] S. Carretero, R. Vuorikari, and Y. Punie, Digcomp 2.1. The Digital Competence Framework for Citizens. With Eight Proficiency Levels and Examples of Use. Luxembourg: Publications Office of the European Union, 2017. 